Supporting Information for

\title{
Copper-mediated deprotection of thiazolidine and selenazolidine derivatives applied to native chemical ligation
}

Naoto Naruse, Daishiro Kobayashi, Kento Ohkawachi, Akira Shigenaga, and Akira Otaka*

Institute of Biomedical Sciences and Graduate School of Pharmaceutical Sciences, Tokushima University, Tokushima 770-8505, Japan.

E-mail:

aotaka@tokushima-u.ac.jp

\section{Contents}

Deprotection of cysteine-containing thiazolidine peptide with copper salt- 1 .................................... S2

Examination of epimerization during thiazolidine opening from model peptide ...............................S3

Deprotection of cysteine-containing thiazolidine peptide with copper salt- 2 ………..................... S4

Examination of disulfide bond formation in copper-mediated ring opening affects ......................... S5

Examination of efficacy of $\mathrm{Cu}(\mathrm{I})$ and $\mathrm{Cu}(\mathrm{II})$ salts for disulfide bond formation .............................. S6

Deprotection of thiazolidine and selenazolidine using less amount of copper salt ............................ S7 
Deprotection of cysteine-containing thiazolidine peptide with copper salt-1

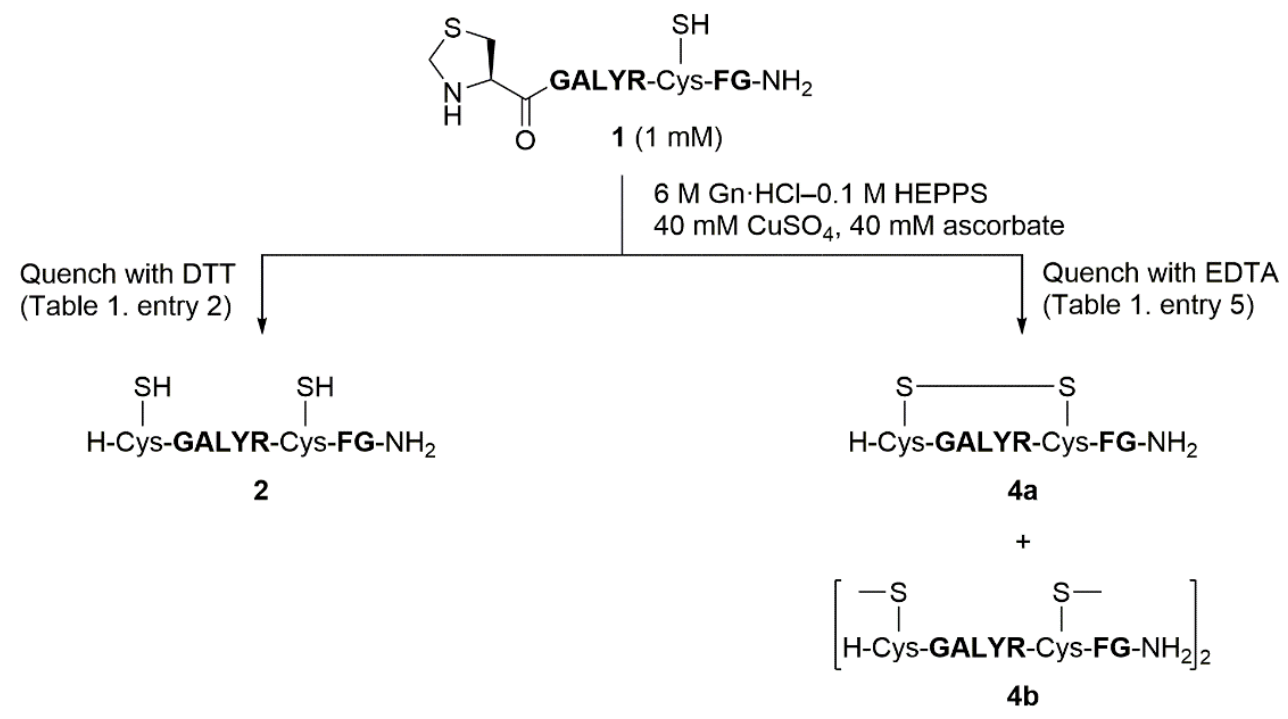

(a)

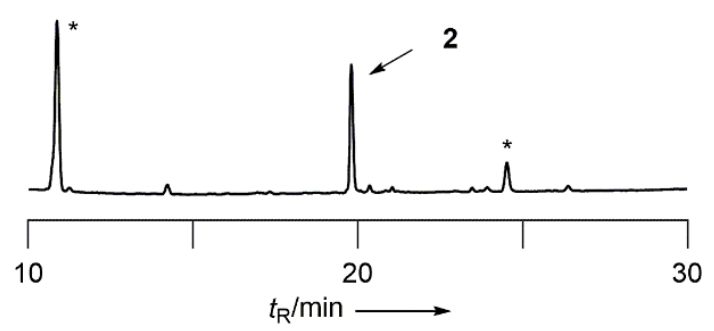

(b)

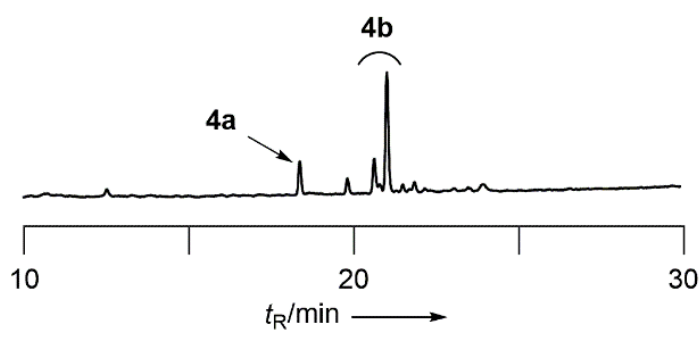

Figure S1. Analytical HPLC charts of crude reaction material. (a) Table 1. entry $2(t=1 \mathrm{~h}$ ); (b) Table 1. entry $5(t=45 \mathrm{~min})$. Analytical HPLC conditions: linear gradient of $0.1 \% \mathrm{TFA} / \mathrm{CH}_{3} \mathrm{CN}$ in $0.1 \%$ $\mathrm{TFA} / \mathrm{H}_{2} \mathrm{O}, 5 \%$ to $45 \%$ over 30 min. *Non-peptide impurity. 
Examination of epimerization during ring-opening thiazolidine from model peptide
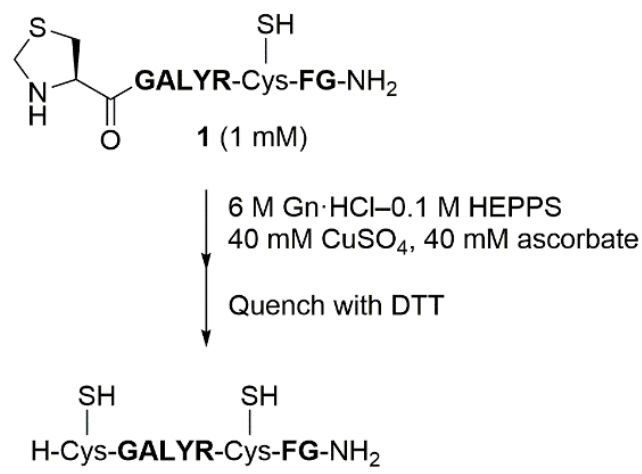

2

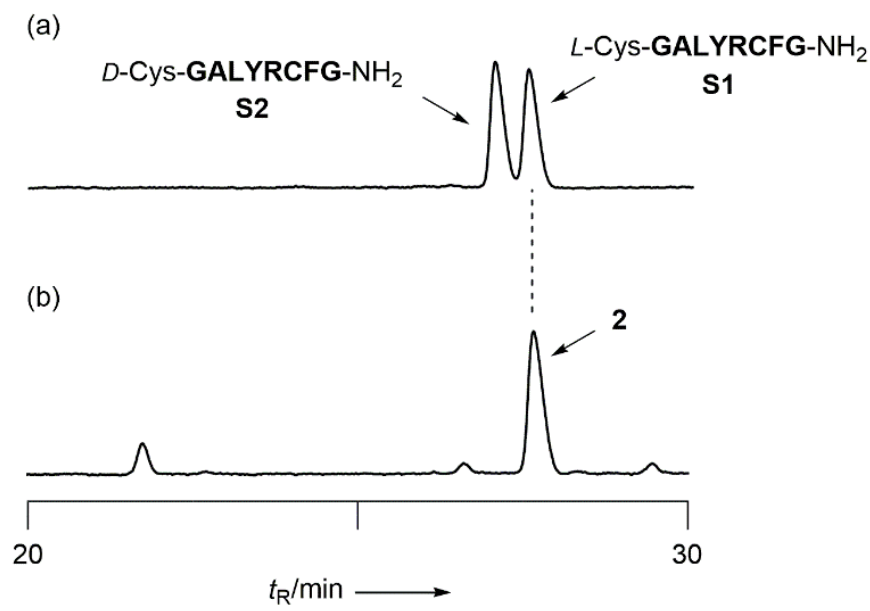

Figure S2. Verification of epimerization of N-terminal chiral amino acids during thiazolidine opening from model peptide (1). (a) Co-injection $\mathbf{S 1}$ with $\mathbf{S 2}$; (b) crude reaction material, ring-opening thiazolidine $(t=1 \mathrm{~h})$. Analytical HPLC conditions: linear gradient of $0.1 \% \mathrm{TFA} / \mathrm{CH}_{3} \mathrm{CN}$ in $0.1 \%$ $\mathrm{TFA} / \mathrm{H}_{2} \mathrm{O}, 15 \%$ to $25 \%$ over $30 \mathrm{~min}$. 
Deprotection of cysteine-containing thiazolidine peptide with copper salt-2

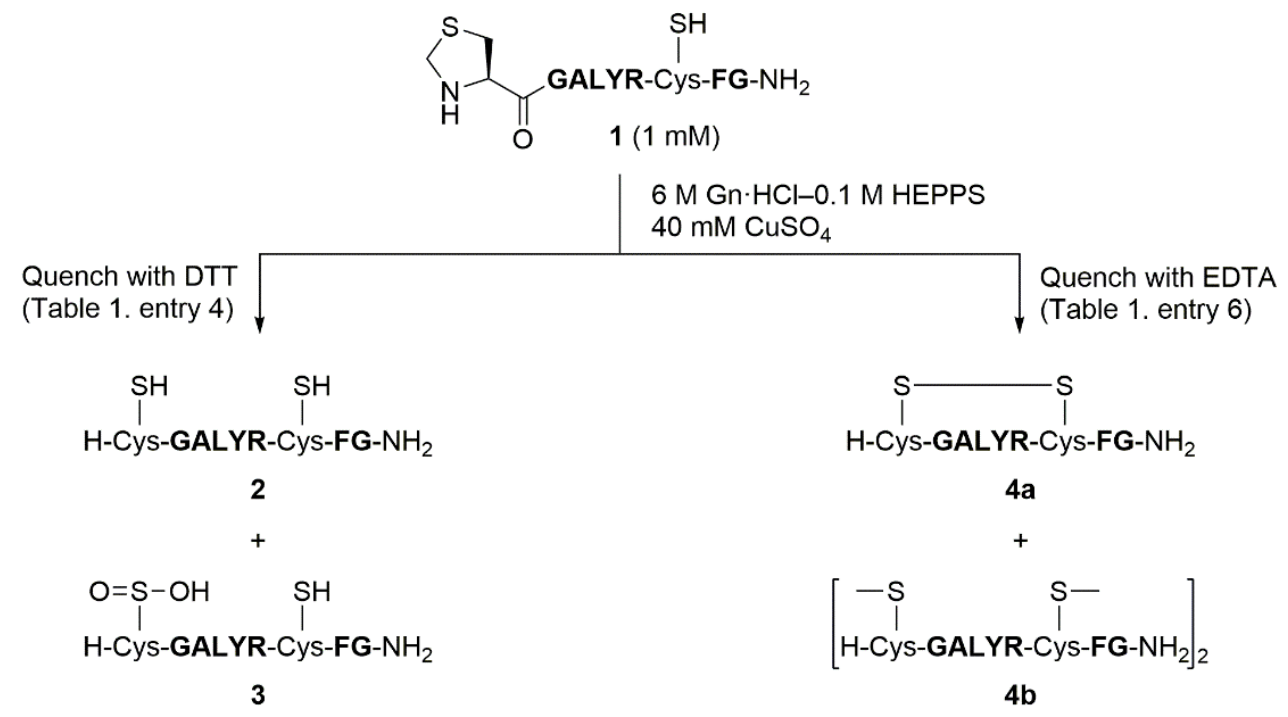

(a)

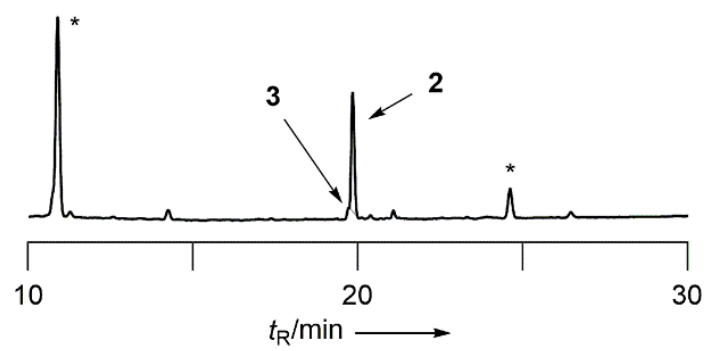

(b)

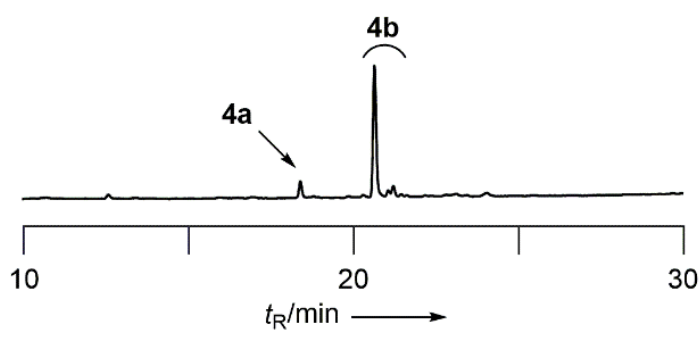

Figure S3. Analytical HPLC charts of crude reaction material. (a) Table 1. entry 4 ( $t=1 \mathrm{~h}$ ); (b) Table 1. entry $6(t=45 \mathrm{~min})$. Analytical HPLC conditions: linear gradient of $0.1 \% \mathrm{TFA} / \mathrm{CH}_{3} \mathrm{CN}$ in $0.1 \%$ $\mathrm{TFA} / \mathrm{H}_{2} \mathrm{O}, 5 \%$ to $45 \%$ over 30 min. *Non-peptide impurity. 
Examination of disulfide bond formation in copper-mediated ring opening affects

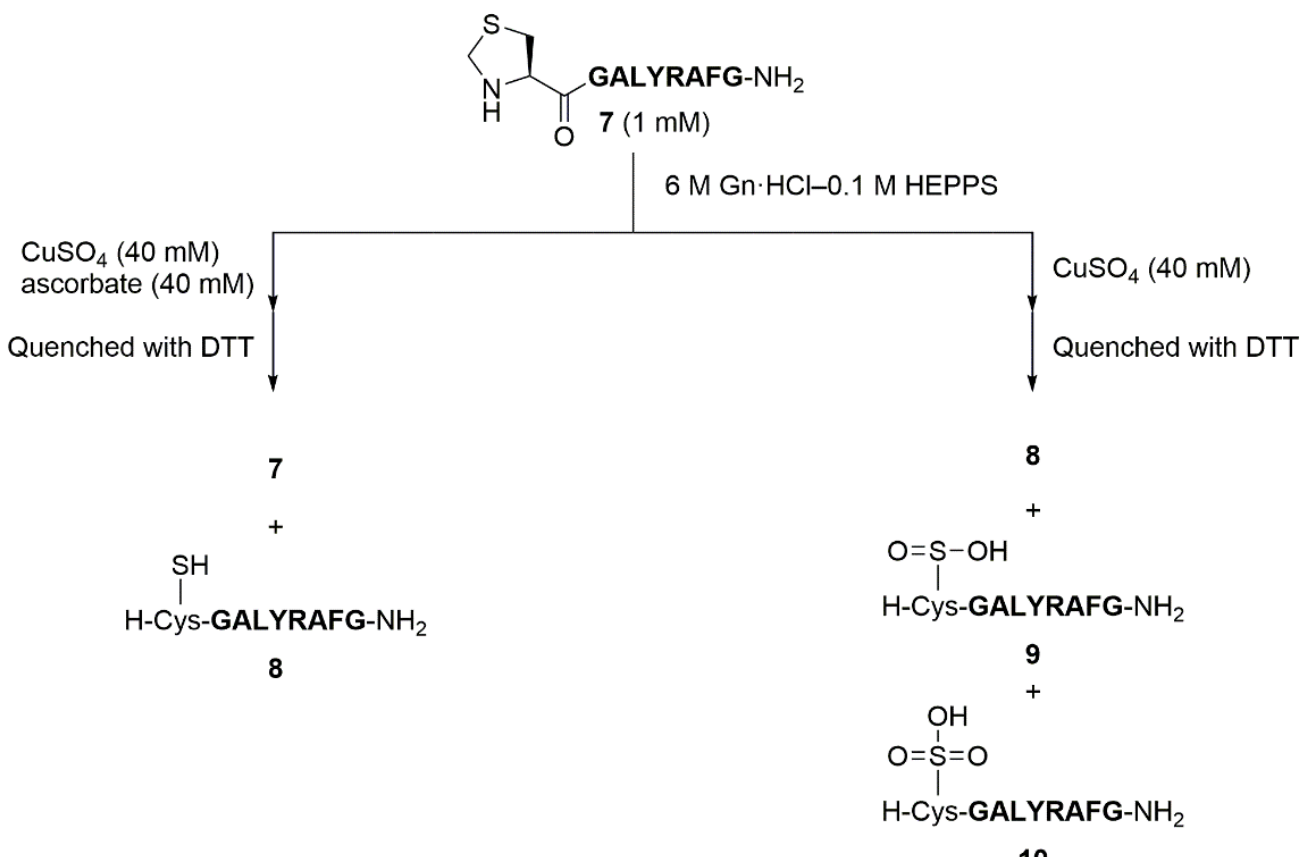

(a)

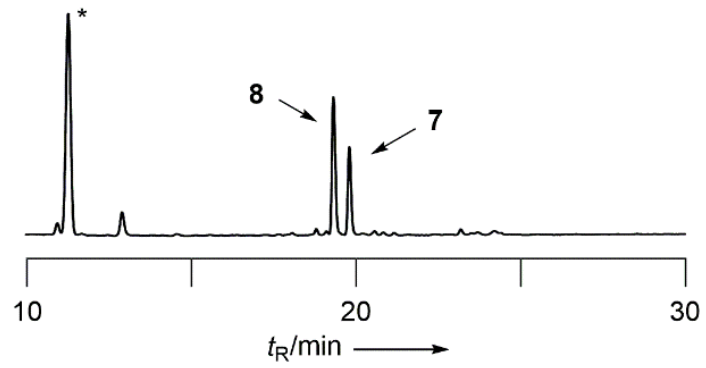

(b)

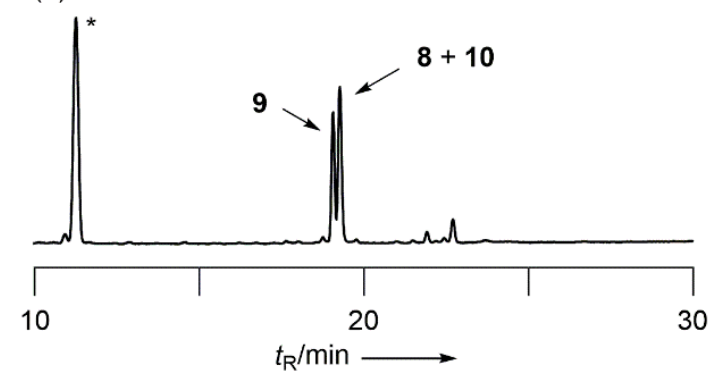

Figure S4. Analytical HPLC charts of crude reaction material. (a) In the presence of $40 \mathrm{mM} \mathrm{CuSO}_{4}$ and $40 \mathrm{mM}$ ascorbate $(t=1 \mathrm{~h})$; (b) in the presence of $40 \mathrm{mM} \mathrm{CuSO}_{4}(t=1 \mathrm{~h})$. Analytical HPLC conditions: linear gradient of $0.1 \% \mathrm{TFA} / \mathrm{CH}_{3} \mathrm{CN}$ in $0.1 \% \mathrm{TFA} / \mathrm{H}_{2} \mathrm{O}, 5 \%$ to $45 \%$ over $30 \mathrm{~min}$. *Nonpeptide impurity. 
Examination of efficacy of $\mathrm{Cu}(\mathrm{I})$ and $\mathrm{Cu}(\mathrm{II})$ salts for disulfide bond formation

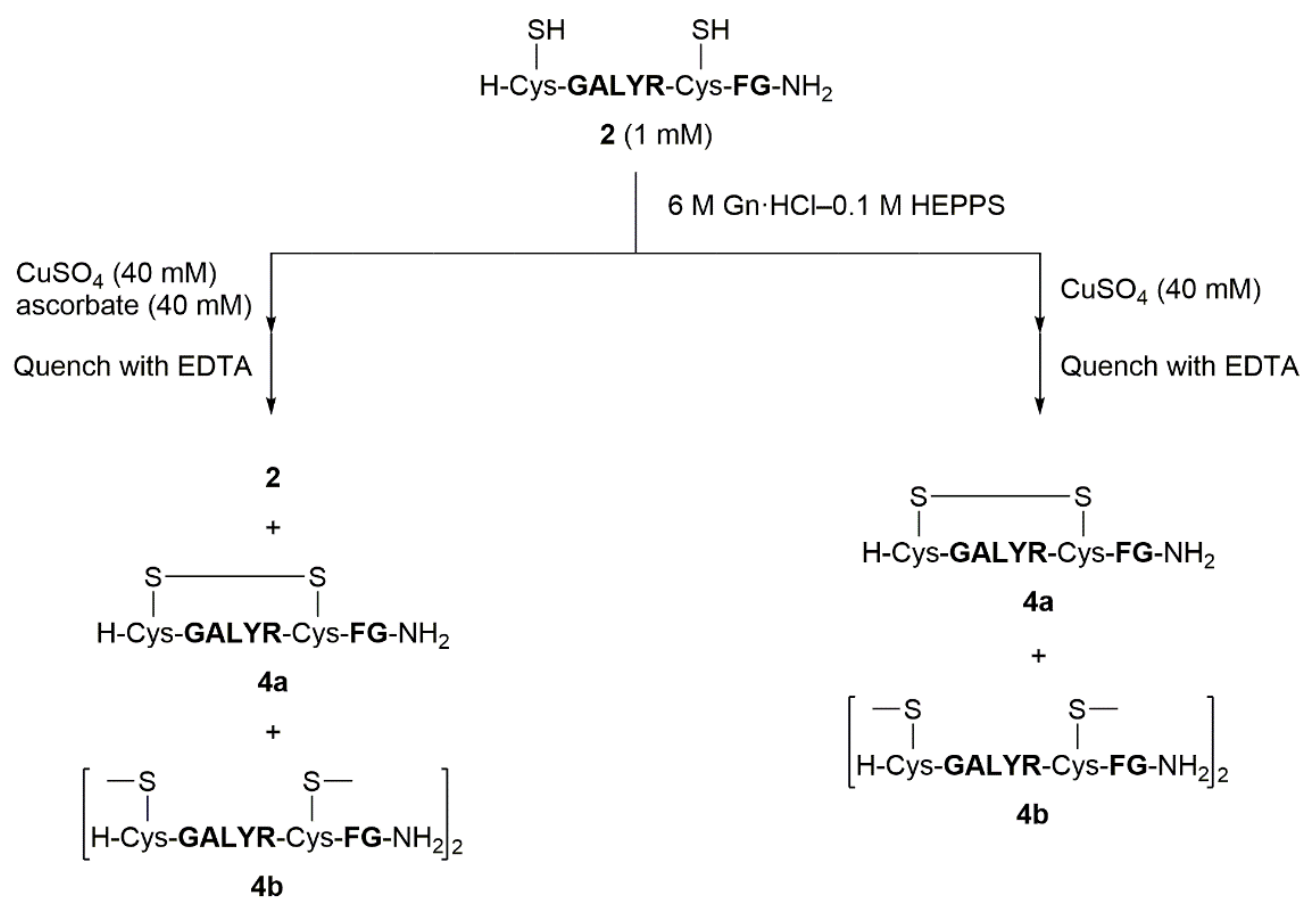

(a)

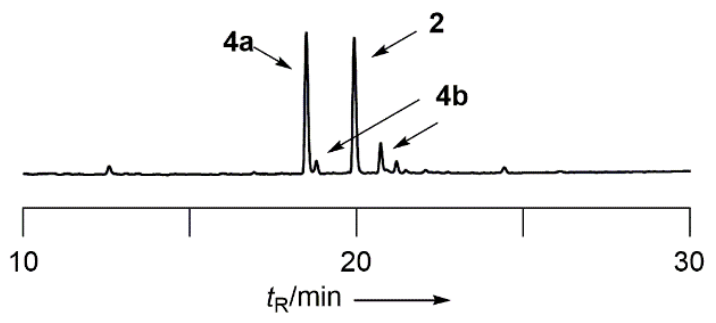

(b)

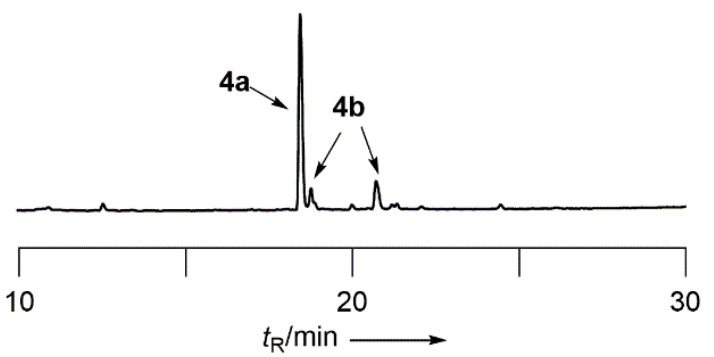

Figure S5. Analytical HPLC charts of crude reaction material. (a) In the presence of $40 \mathrm{mM} \mathrm{CuSO}_{4}$ and $40 \mathrm{mM}$ ascorbate $(t=10 \mathrm{~min})$; (b) in the presence of $40 \mathrm{mM} \mathrm{CuSO}_{4}(t=10 \mathrm{~min})$. Analytical HPLC conditions: linear gradient of $0.1 \% \mathrm{TFA} / \mathrm{CH}_{3} \mathrm{CN}$ in $0.1 \% \mathrm{TFA} / \mathrm{H}_{2} \mathrm{O}, 5 \%$ to $45 \%$ over $30 \mathrm{~min}$. 
Deprotection of thiazolidine and selenazolidine using less amount of copper salt

$\left.\right|_{\mathrm{O}} ^{\mathrm{S}} \underset{\mathbf{1}(1 \mathrm{mM})}{\substack{\mathrm{SH} \\ \text { GALYR-Cys-FG-NH}}}$

$6 \mathrm{M} \mathrm{Gn} \cdot \mathrm{HCl}-0.1 \mathrm{M}$ HEPPS

$2 \mathrm{mM} \mathrm{CuSO}_{4}, 2 \mathrm{mM}$ ascorbate

Quench with DTT

$+$

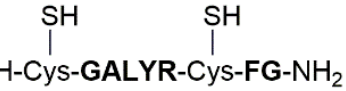

2

(a)

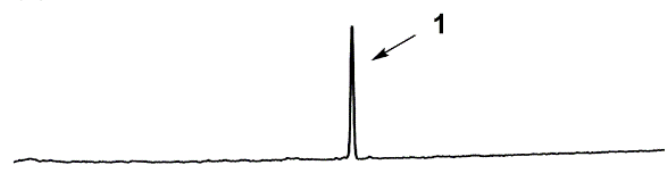

(b)

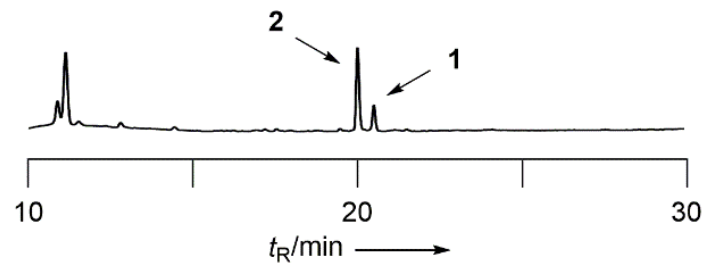

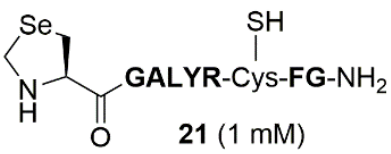

$6 \mathrm{M} \mathrm{Gn} \cdot \mathrm{HCl}-0.1 \mathrm{M}$ HEPPS

$2 \mathrm{mM} \mathrm{CuSO}_{4}, 2 \mathrm{mM}$ ascorbate

Quench with EDTA

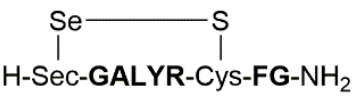

22

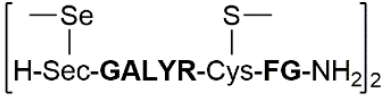

23

(c)

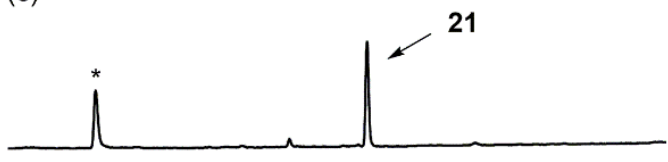

(d)

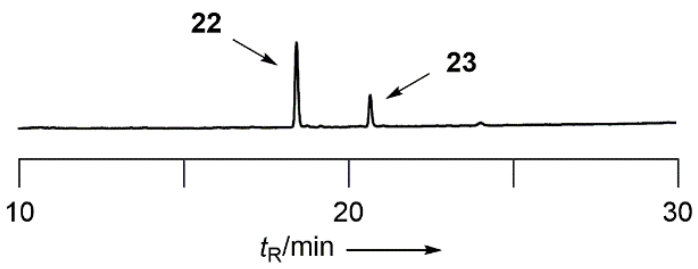

Figure S6. Analytical HPLC charts of crude reaction material. (a) $(t=0 \mathrm{~h})$; (b) $(t=1 \mathrm{~h})$; (c) $(t=0 \mathrm{~h})$; (d) $(t=45 \mathrm{~min})$. Analytical HPLC conditions: linear gradient of $0.1 \% \mathrm{TFA} / \mathrm{CH}_{3} \mathrm{CN}$ in $0.1 \% \mathrm{TFA} / \mathrm{H}_{2} \mathrm{O}$, $5 \%$ to $45 \%$ over 30 min. *Non-peptide impurity. 